\title{
Marital Quality and Paternal Involvement: Interconnections of Men's Spousal and Parental Roles
}

Sampson Lee Blair, Deeann Wenk, Constance Hardesty

First Published February 1, 1994 Research Article

\section{Article Information}

Volume: 2 issue: 3 , page(s): 221-237

Issue published: February 1, 1994

First page (221):

Marital Quality and Paternal Involvement:

Interconnections of Men's Spousal and

Parental Roles

\author{
SAMPSON LEE BLAIR \\ DEEANN WENK \\ Constance Hardesty \\ Department of Sociology \\ The University of Oklahoma
}

\begin{abstract}
Among family rescarchers, the study of parenting and parenthood has generated a large volume of research literature. Researchers have sought to understand better how individuals are socialized into the parental role (Gage \& Christensen, 1991), how the stress of parenthood affects men and women differently (Scott \& Alwin, 1989), and how parenthood can influence marital relationships (McHale \& Huston, 1985; Waldron \& Routh, 1981). The relationship between marital quality and parenting, however, is of particular interest, given that the vast majority of the research in this area has concluded that the presence of children is associated with decreases in the quality of the marital union (Abbott \& Brody, 1985; I.eMasters \& DeFrain, 1989).

Whereas some studics have established that parenthood may be deletcrious to marital quality, the reverse association - the effect of marital quality on parenting - is seemingly overlooked. And it is equally appropriate to consider the effects marital quality may have on parenting (Belsky, Youngblade, Rovine, \& Volling, 1991). If participation in the parental role leads to decreases in marital quality, it is equally important, if not more so, to understand the effects marital quality has on parenting and parenting involvement.

This study will provide an analysis from the perspective of marital quality influencing parental involvement. We propose that the relationship will be stronger for fathers than for mothers because men tend to have unified vicws of the parent/spouse role (Pleck, 1987a) while women perceive these roles as distinct (Komter, 1989). It is appropriate to assume, then, that paternal relations will be more susceptible to the naturc of the spousal relationship than will maternal relations. Our analyses will be directed toward determining the sources of variation in the parental experience as affected by the different dimensions of marital quality for mothers and fathers.
\end{abstract}

